\title{
Mobile AR for Cultural Heritage Site towards Enjoyable Informal Learning: A Revised Conceptual Model
}

\author{
Ulka Chandini Pendit*, Syamsul Bahrin Zaibon, Juliana A. Abu Bakar \\ School of Multimedia Technology \& Communication, Universiti Utara Malaysia \\ *ulka.chandinipendit@gmail.com
}

\begin{abstract}
The need of visitor has been changed in tourism which is to learn and have meaningful experience. However, Mobile Augmented Reality technology that caters enjoyable informal learning in cultural heritage site is still limited. Therefore a conceptual model is proposed to guide developers in developing such mobile AR application to promote enjoyable informal learning. This article describes the proposed model which is called as a 'conceptual model of mobile AR for cultural heritage site towards enjoyable informal learning'. Expert review and focus group discussion methods were conducted to evaluate the proposed model are also explained in this article. Prior to the evaluation process, a field study was also conducted to discover novel components of enjoyable informal learning content in cultural heritage site. The results of all methods conducted were contributed to the development of a conceptual model. The conceptual model consists of two levels which in the first level; it contains three main components (mobile AR technology, enjoyable informal learning, and cultural heritage site) and in the second level of the model provides detail information which contains the elements of each component.
\end{abstract}

Keywords: Mobile augmented reality, enjoyable, informal learning, cultural heritage site, conceptual model

\section{Introduction}

Augmented Reality (AR) technology has made a breakthrough in cultural heritage site. It provides an alternative way to enhance visitor's experience in learning in cultural heritage site. Some examples of AR application for cultural heritage site are virtual 3D models in La Lonja Site, Valencia for facilitating interpretation(Puyuelo, Higón, Merino, \& Contero, 2013), Techcooltour that provides various content, such, 3D model, 3D virtual character, video, 360 degree panorama for Roman and Byzantine heritage sites(Wachelka, 2013) and interactive AR tourist guide provides3D animations with the route that display the cultural heritage sites (Fino, Martín-Gutiérrez, Fernández, \& Davara, 2013). However, as the new need of learning in tourism(Park, Nam, \& Shi, 2006), mobile AR for cultural heritage that caters the enjoyable informal learning is still limited (Pendit \& Zaibon, 2014). Therefore, a conceptual model of mobile AR for cultural heritage site towards enjoyable informal learning has been constructed (Pendit \& Zaibon, 2014). Then, the conceptual model was evaluated through expert review and focus group discussion methods. Before the evaluation was taken placed, a field study was also conducted to discover novel components of enjoyable informal learning content in cultural heritage site. All steps have resulted useful feedback to refine the proposed conceptual model. This article explains a revised version of the proposed conceptual model of mobile AR for cultural heritage towards enjoyable informal learning. The steps of evaluation of conceptual model which include, expert review, and focus group discussion are explained in the next sections.

\section{Literature Review}

Expert review was conducted to evaluate the conceptual model. It involved seven experts, from the field of AR, learning, and cultural heritage (refer to table 1). The process of review was done via email communication by sending the review form and conceptual model descriptions. The review form consists of four main sections, which are, introduction, expert's details, explanation of conceptual model and review section. The experts need to answer seven questions related with the terminologies, theories, and components of the conceptual model. The first question asks about the terminology used in the model with three choices of answers: needs very detail explanation, needs some explanation and is easy to understand. The second question asks about the relevancy of proposed elements in the components of conceptual design model, which are: media elements, activity, navigation, social interaction, games, presentation style and mobile technology. The choices of answers are, some are definitely not relevant, some may be not relevant and all are relevant. The third question asks about the relevancy of the proposed theories, which 
are: multimedia learning theory, mindfulness theory, constructivism theory, situated learning theory, experiential learning theory, and collaborative learning theory. The choices of answers are relevant and not relevant. Each question provides the comment section. The fourth question asks whether the connection of theories and components is logical or not. The fifth question asks whether the conceptual model is usable to the development of mobile AR for enjoyable informal learning. The sixth question asks whether the conceptual model is readable or not. The choices of answers of question number four to question number six are yes and no. Finally, in the last question is to know their others comment about the conceptual model.

Table 1: Demographic Profiles of Experts

\begin{tabular}{|c|c|c|c|c|c|}
\hline No & Gender & Age(year) & Education & Field of Expertise & $\begin{array}{l}\text { Experience } \\
\text { (year) }\end{array}$ \\
\hline 1 & Female & 36 & $\mathrm{PhD}$ & AR & 6 years \\
\hline 2 & Female & 38 & $\mathrm{PhD}$ & $\begin{array}{l}\text { HCI, Museum Learning \& } \\
\text { Mobile learning }\end{array}$ & 5 years \\
\hline 3 & Male & 35 & $\mathrm{PhD}$ & AR \& Computer Vision & 6 years \\
\hline 4 & Male & 56 & $\mathrm{PhD}$ & Learning & 5 years \\
\hline 5 & Female & - & $\mathrm{PhD}$ & VR and AR & 7 years \\
\hline 6 & Male & - & PhD & $\mathrm{AR}$ & 5 years \\
\hline 7 & Female & - & $\mathrm{PhD}$ & Multimedia & 5 years \\
\hline
\end{tabular}

\section{Finding}

The experts consider the conceptual model has terminology that is easy to understand, relevant elements, relevant theories, logical flow, usable and readable. The responses from experts are illustrated in figure 1 until figure 4.

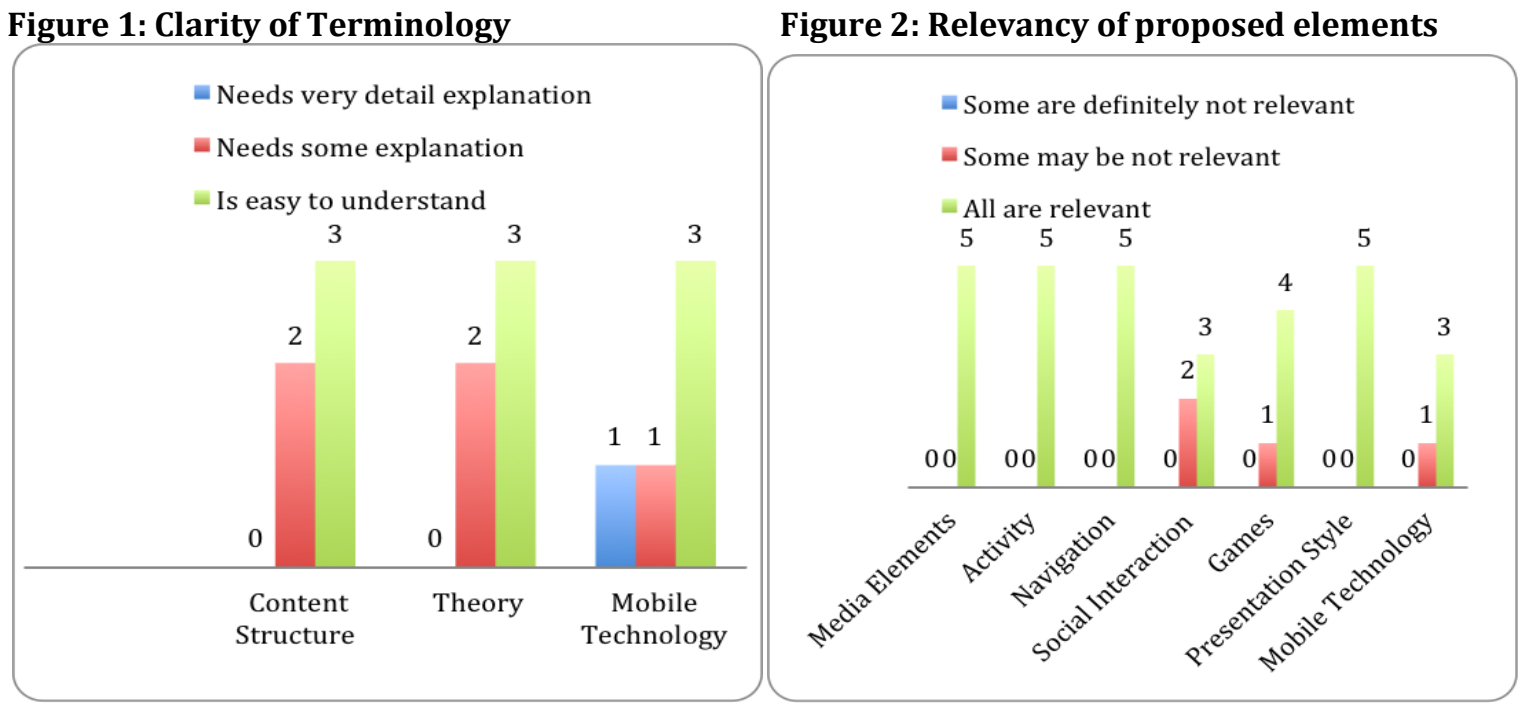

Figure 3: Relevancy of proposed theories conceptual model

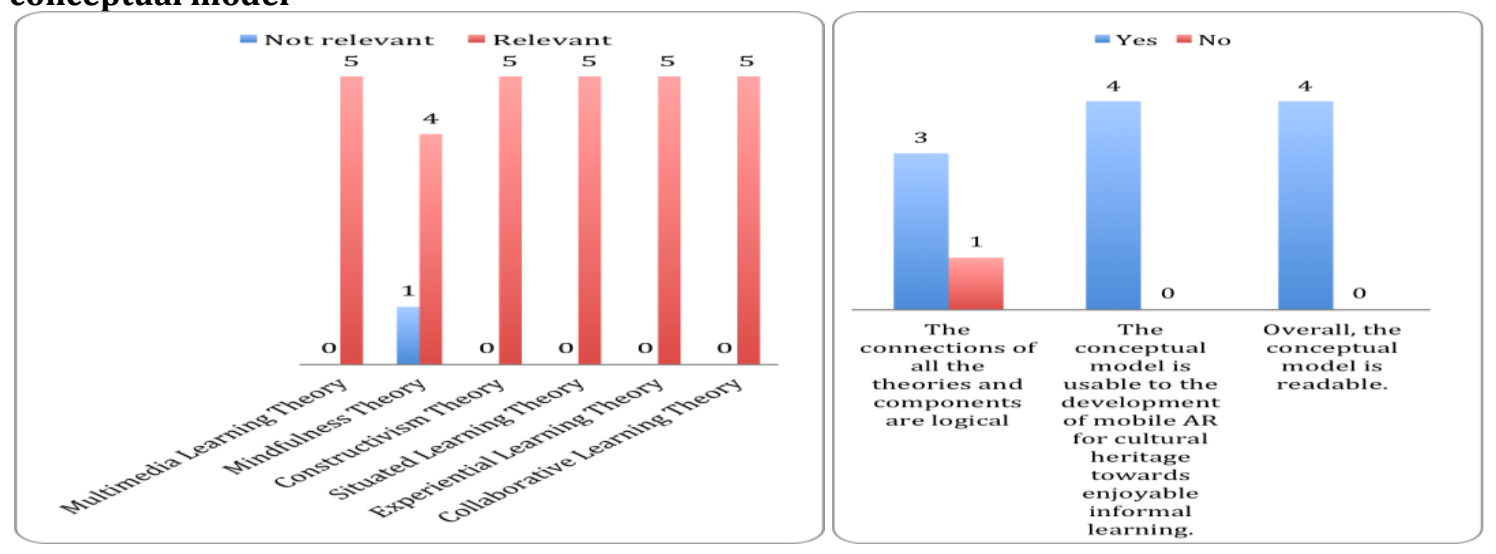


In addition, experts also were given space for detail comments regarding the conceptual model (refer to table 3). Majority of comments were addressed to the component of mobile technology that should be presented with category for different function of each element. Experts also suggested some elements to be included in content structure component and recommended to change the terminologies to give clear meaning. Besides, the chosen theory and link between the theory and the content structure element are also needed to be revised. However, the most important comment is the lack of novel component in the model that makes it is too generic and too brief for the proposed conceptual model.

\section{Table 3: Feedback from Experts}

Experts Comments

(a) The media elements can be divided into two types: passive and active content. active content is the content that includes user interaction, such as: activity, social interaction and games

(b) More details on the theory is needed to understand about their relevancy on supporting the content structure

(c) The elements in mobile technology should be put into category, such, core technologies for AR and necessary devices for AR. The terms "sensor" and "mobile technology" are also not

Expert 1 proper.

(d) Should add taking picture and interacting with content in the activity component.

(e) The term "chat" in social interaction is not proper.

(f) It is possible to add virtual views in the presentation style.

(g) Strength: the conceptual model is feasible and worthwhile to improve the informal learning experience in cultural heritage site. Weakness: Most of components have been presented in previous works and novel components in informal learning are not sufficient.

(h) Provide details for each component in hierarchy or layers than list of individual elements

(i) Validate the conceptual model through user evaluation

(a) Provide more detail explanation on content structure and theory

(b) The relationship between the components in mobile technology is not understandable. Provide category for different function of component and add display component.

(c) Activities, navigation and manipulation can be added as well as activity related with media elements, such, see and hear in activity component

(d) Provide navigation for museum and indoor cultural heritage environment

(e) Add shared view with single display in social interaction

Expert 2 (f) Provide other type of games, such: 3D puzzle

(g) Provide more explanations in the presentation style

(h) MLT theory and collaborative learning theory should link to other elements in content structure

(i) Mindfulness theory should consider personal cognitive style and traits of visitor that may influence the social interaction

(j) Constructivism theory, situated learning theory and experiential learning theory should be linked to media elements

(a) Consider HCI theory as AR system should be interactive in real time (Azuma, 1997)

(b) Provide personal setting such, select language in the opening/closing component instead login/register

(c) Differentiate between audio and sound in media elements. Also distinguish different type objects, such, static and dynamic. the elements also can respond to user interaction

(d) Consider to provide a complete map of the site and recommended route for the visit in navigation

(e) Clarify the term "chat". differentiate between virtual and real (face to face) interaction in

Expert 3 social interaction

(f) Clarify the term "separated augmented view" in presentation style

(g) Provide category for different function of each mobile technology component, such, hardware, software and process

(h) Conceptual model is well presented and logical. However, it misses the term "interaction" as it is a fundamental part of AR system. The mobile technology component also needs to be better presented.

(i) Consider to add validation/evaluation component in content structure on evaluating the learning process

Expert 4 The proposed model is thorough and detail. I expect the outcomes of this model would be 
good if the learning activities can be well-arranged. familiar but others are well aligned with the teaching and learning methods possible through AR.

(b) The missing major element is the outcome of the variable that will be measured.

(a) The proposed elements in content structure are too generic and are applicable to any kind of applications.

(b) The connections of all theories ad components are somewhat logical

Expert 6 (c) The conceptual model is partly usable to the development of AR for cultural heritage towards enjoyable informal learning.

(d) The conceptual model is too brief.

(e) Expand and detail out to be specific in AR and cultural heritage

Expert 7 The conceptual model is good but the scope is too wide that it should focus more on enjoyable learning.

Field Study of Enjoyable Informal Learning Content in Cultural Heritage Site: In discovering the novel component for the conceptual model, a field study was conducted. The field study was conducted on $31^{\text {st }}$ of May, 2014 at Lembah Bujang Archaeological Site, Kedah. There were five respondents from 17 to 49 years old who participated in the study. The purpose of field study is to define the criteria of content for enjoyable informal learning in cultural heritage site. Structured interview question was used as the instrument to gather the data from respondent. The question are related with the content that is suitable for enjoyable informal learning in cultural heritage site, such, type of media, navigation, games, activity and interaction. There are seventeen questions with fifteen multiple choice questions and two open-ended questions. Table 4 shows the responses of the field study.

\section{Table 4: Responses of Field Study}

\begin{tabular}{|c|c|c|}
\hline No & Category & Responses \\
\hline 1 & Preferences of Media & Image, animation and video \\
\hline \multirow[t]{2}{*}{2} & Text & a. Show point by point \\
\hline & & b. $\quad$ Provide big size of font \\
\hline 3 & 3D Model & Overlays certain part that is lost \\
\hline 4 & 3D Character & Represent the noble people in the past \\
\hline \multirow[t]{2}{*}{5} & Image & a. Overlays certain part that is lost \\
\hline & & Old pictures with year in chronological order \\
\hline \multirow[t]{4}{*}{6} & Audio & Provide history of cultural heritage site \\
\hline & & Provide history of cultural heritage site in narrative storytelling \\
\hline & & $\begin{array}{l}\text { c. Provide history of cultural heritage site in narrative storytelling } \\
\text { and the narrator has the same age with visitor }\end{array}$ \\
\hline & & d. $\quad$ The length of audio should be in 3 to 5 minutes \\
\hline 7 & Sound & Provide ambience of heritage site \\
\hline \multirow[t]{2}{*}{8} & Animation & $\begin{array}{l}\text { a. Provide history of cultural heritage site with the noble people as } \\
\text { the character in narrative storytelling }\end{array}$ \\
\hline & & b. $\quad$ Length of $3 \mathrm{D}$ animation is 5 to 10 minutes \\
\hline \multirow[t]{4}{*}{9} & Video & $\begin{array}{l}\text { a. Provide video of cultural heritage site with noble people as the } \\
\text { character }\end{array}$ \\
\hline & & $\begin{array}{l}\text { b. Provide video of cultural heritage site with noble people as } \\
\text { character in narrative storytelling }\end{array}$ \\
\hline & & $\begin{array}{l}\text { Provide video of cultural heritage site with the noble people as the } \\
\text { character in narrative storytelling and the narrator has the same age with } \\
\text { visitor }\end{array}$ \\
\hline & & d. Length of video is 5 to 10 minutes \\
\hline 10 & $\begin{array}{l}\text { Preferences to learn } \\
\text { based on interest }\end{array}$ & No, it is not preferable to learn based on interest \\
\hline \multirow[t]{3}{*}{11} & Navigation & Shows other interest places around the cultural heritage site \\
\hline & & Show the path visitor has visited \\
\hline & & Show the site based on history in chronological order \\
\hline \multirow[t]{3}{*}{12} & Activity & Add / edit information \\
\hline & & Take picture \\
\hline & & Create notes \\
\hline
\end{tabular}




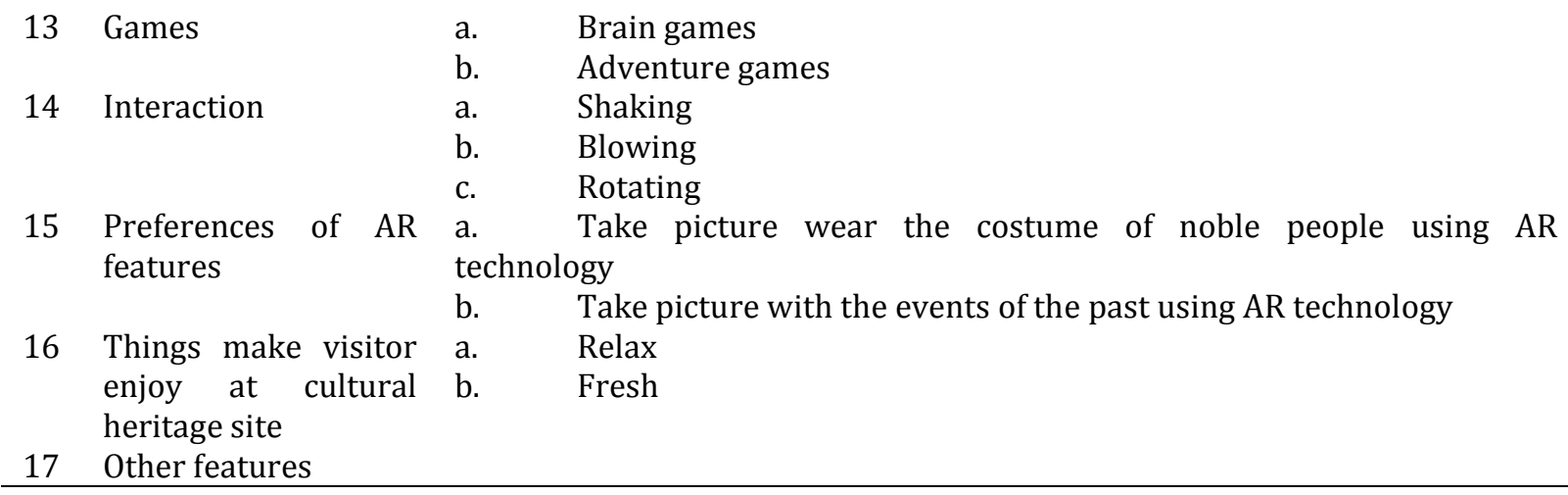

The findings of the field study provide clear criteria and specification of enjoyable informal learning content in cultural heritage site. Image, animation, and video are the three types of media that visitor would like to have the most while learning at cultural heritage site. Besides that, each media has its own criteria to present the information that induces the enjoyable informal learning environment. The new features were discovered for navigation, activity and games element. Interaction and entertainment are two new components that have been figured out in the field study. Each of them has its own features which are preferred by visitor. Other feature that is recommended to be added in the mobile application is music that is related with the cultural heritage site. All the responses are gathered and collected as the records to improve the conceptual model.

Focus Group Discussion: Focus group discussion was conducted to evaluate the conceptual model. Focus group involved 8 experts in computer, information technology, and creative industry fields. The demographic profile of experts is provided in table 5 .

Table 5: Demographic Profile of Expert

\begin{tabular}{|c|c|c|c|c|c|}
\hline No & Age & Gender & Education & Field of Expertise & Year of Experience \\
\hline Expert 1 & 33 & Male & Master & $\begin{array}{l}\text { Software } \\
\text { Engineering }\end{array}$ & 10 years \\
\hline Expert 2 & 39 & Male & $\mathrm{PhD}$ & $\begin{array}{l}\text { VR \& Computer } \\
\text { Graphics }\end{array}$ & 15 years \\
\hline Expert 3 & 30 & Male & Master & Creative Business & 12 years \\
\hline Expert 4 & 28 & Male & Bachelor & Creative Industry & 9 years \\
\hline Expert 5 & 43 & Male & Master & Image Processing & 5 years \\
\hline Expert 6 & 39 & Male & Master & Accessibility & 13 years \\
\hline Expert 7 & 37 & Female & Master & $\begin{array}{l}\text { VR, AR \& E- } \\
\text { Learning }\end{array}$ & 10 years \\
\hline Expert 8 & 34 & Female & Master & $\begin{array}{l}\text { Multimedia } \\
\text { Application }\end{array}$ & 5 years \\
\hline
\end{tabular}

The focus group discussion was started by presentation about conceptual model. Then the experts were asked to review the conceptual model based on the review form. The experts were also allowed to ask for any question related to the conceptual model. The focus group discussion was lasted for one and half hour. The results are illustrated in table 6. Overall, the focus group has resulted a fruitful discussion. Most of expert considered mobile AR technology should be connected with the content element component to create the interrelated connection with all components in conceptual model. Further, other important feedbacks are to add the interaction component and to focus on enjoyable informal learning that becomes the main contribution of the conceptual model. 


\begin{tabular}{|c|c|}
\hline No & Comments \\
\hline \multirow[t]{3}{*}{ Expert 1} & $\begin{array}{l}\text { a. Include informal learning theory } \\
\text { b.Emphasized on interactivity and enjoyable informal learning for content element } \\
\text { component }\end{array}$ \\
\hline & $\begin{array}{l}\text { c. The connection in conceptual model couldn't be seen } \\
\text { d.Focus more on enjoyable informal learning and the main contribution of conceptual model }\end{array}$ \\
\hline & a. $\quad$ The theory is relevant but have to be presented more clearly \\
\hline \multirow{3}{*}{ Expert 2} & Add informal learning theory \\
\hline & Consider "tangible AR" for terms \\
\hline & Add interaction component \\
\hline \multirow{3}{*}{ Expert 3} & Connect the mobile AR technology and content element component \\
\hline & It is should be possible to add more elements in content element \\
\hline & $\begin{array}{l}\text { Create general model to be used for other field related with mobile AR or enjoyable } \\
\text { informal learning or cultural heritage site }\end{array}$ \\
\hline Expert 4 & $\begin{array}{l}\text { a. } \quad \text { Connection between all components should be improved } \\
\text { b. }\end{array}$ \\
\hline \multirow{2}{*}{ Expert 5} & $\begin{array}{l}\text { Mobile AR technology component should be improved } \\
\text { The terms should be improved }\end{array}$ \\
\hline & $\begin{array}{l}\text { The connection between mobile AR, theories and content element is not clear } \\
\text { The conceptual model is not clear enough }\end{array}$ \\
\hline \multirow{5}{*}{ Expert 6} & The theory should be reconstructed in order to be understood \\
\hline & Consider to combine content element with mobile AR technology \\
\hline & Some terms are not clear, such as, "provided for each site" \\
\hline & Combine all component with mobile AR technology \\
\hline & Differentiate the uniqueness of mobile AR technology component from the existing \\
\hline \multirow{3}{*}{ Expert 7} & Add one element special for cultural heritage site in content element \\
\hline & Connection between theory and content element seems logical \\
\hline & c. The term "registration" is not clear \\
\hline Expert 8 & $\begin{array}{l}\text { Create general model consists of three main topics: mobile AR, enjoyable informal learning } \\
\text { and cultural heritage site. }\end{array}$ \\
\hline
\end{tabular}

A Revised Conceptual Model Of Mobile Ar For Cultural Heritage Site Towards Enjoyable Informal LEARNING: The conceptual model has been improvised based on the experts review, field study's findings, and focus group discussion. As a result, three theories are adapted in the model which mostly related to the study; situated learning, mindfulness, and constructivism theories. The content structure term has been changed to 'content element' with the remaining four elements: media elements, navigation, activity, and games with the addition of two new elements: context-awareness and interaction. While, mobile technology term has been changed to 'mobile AR technology' with each element is specified to category. The followings are the explanation of new and revised components:

a. Context-awareness: Context is any information that can be used to characterize the situation of entity (person, place, object that relates with the interaction between user and application) (Dey, Abowd, \& Salber, 2001). Context-aware system uses context to provide information to visitor where the authority depends on the user. Context-awareness function also supports the personalized mobile AR application (Seo, Kim, \& Park, 2011).The supporting elements chosen for the context-awareness component are: 'set the range of distance' and 'set language'. 'Set range of distance' enable users to set the range of distance they would like to have in order to avoid overlapping point of interests. They also able to set their prefered language to learn in cultural heritage site.

b. Interaction: The major goal of AR is to enable user interacts naturally with the virtual object (Vallino, 1998). There are five types of user interaction, namely touch interaction, rubbing and shaking, drag and drop interaction, touching and interacting and motion determination (Zoellner, Stricker, Bleser, \& Pastarmov, 2007). Motion determination is direct interaction based on user gestures, such as, shaking, nodding, leaning, and rotating. These types of user interaction are considered as tangible AR as it provide seamless interaction that allows user to use any input device in physical world to interact with the virtual and physical object (Billinghurst, Kato, \& Poupyrev, 2008). According to field study's result, "blowing" got the highest score followed by shaking and rotating. However, shaking and blowing are two features of 
interaction for mobile AR guide in cultural heritage site suggested by (Toh, Jeung, \& Pan, 2010) that also applied in this study.

c. Content element: Some considerations are dedicated to thecontent element. Audio and video should provide clear intonation and articulation to convey clear understanding to visitor rather than provide the narrator which has the same age with visitor. The image should also shows the cultural heritagevalues, such as, traditional clothes and traditional weapons related with the site. Animation and video are also possible to provide the presentation about history of cultural heritage site in general format besides the presentation of noble people who talks about the history of cultural heritage site in narrative storytelling. The navigation component is added with the feature of recommended route to cultural heritage site and show the map of cultural heritage site. The activity component is the combination of previous features and new features: save information, share information, take picture (take the real environment and take the augmented environment), add/edit information and create notes. The games component is added with the criteria for every game that help the learning to be enjoyable in cultural heritage site. The general information is the new component added that provides information, such as opening/closing hours, address, ticket price and special events. However, the entertainment element is merged into take picture element in the activity.

d. Mobile AR Technology: According to (Höllerer \& Feiner, 2004) and (Azuma, 1997), there are seven requirements for mobile AR systems, which are, computational platform, display, registration/calibration, tracking, rendering, wearable input (camera), interaction, wireless networking and data storage and access technology. Below is the comparative analysis of process in mobile AR technology of seven selected mobile AR for cultural heritage site (refer to table 7). The explanation of these seven mobile AR applications are provided in (Pendit \& Zaibon, 2014):

Table 7: Comparative Analysis for Process of Mobile AR Technology

\begin{tabular}{llllllll}
\hline Process & MAR1 & MAR2 & MAR3 & MAR4 & MAR5 & MAR6 & MAR7 \\
\hline Tracking & 1 & 1 & 1 & 1 & 1 & 1 & 1 \\
Positioning & 1 & 1 & 1 & 1 & 1 & 1 & 1 \\
Interaction & 0 & 1 & 1 & 1 & 0 & 0 & 1 \\
Calibration & 1 & 1 & 1 & 1 & 1 & 1 & 1 \\
Rendering & 1 & 1 & 1 & 1 & 1 & 1 & 1 \\
\hline
\end{tabular}

The consideration for taking the process is based on the score conditions: (score 1-3) discarded and (score 4-7) compulsory. The score above shows that all applications have score in the range of 3 to 5 which considered all components are compulsory. Besides, the hardware components consist of handheld devices (smart-phones, tablets) that include sensors and touch screens. Sensors include camera, GPS, compass, accelerometer and magnetometer that is used for tracking and positioning. Touch screen is used as the interaction medium between user and virtual object. Software component consists of AR libraries and data storage. AR libraries are the software development kit for developing AR, such, AR Toolkit, Studierstube Tracker, build AR and Metaio. Data storage is needed to store the virtual data to be augmented to the real environment. The improvement of the mobile AR technology component is obtained through expert review feedback. Based on the focus group feedback, the proposed conceptual model is divided in two levels, the first level that consist of three main components (mobile AR technology, enjoyable informal learning, and cultural heritage site) (refer to figure 5) and the second level is the detail version of the first level (refer to figure 6).

\section{Conclusion}

Mobile AR for cultural heritage site towards enjoyable informal learning is highly needed to be implemented in cultural heritage site due to the needs of visitor of learning while visiting the cultural heritage site. Therefore, a conceptual model was developed to help developer for developing mobile AR for cultural heritage sites which focuses on enjoyable informal learning. The conceptual model was revised through expert review and focus group discussion. The revised conceptual model consists of two levels, first level contains three main components (mobile AR technology, enjoyable informal learning and cultural heritage site) and second level provides detail elements of main components. These steps found the proposed conceptual model is useful but it needs improvement for mobile AR for cultural heritage site that caters enjoyable informal learning development. The future research is to develop a prototype based 
on conceptual model and evaluate the prototype to measure visitor's enjoyable informal learning experience.

Figure 5: Proposed Conceptual Model of Mobile AR for Cultural Heritage Site towards Enjoyable Informal Learning (First Level)

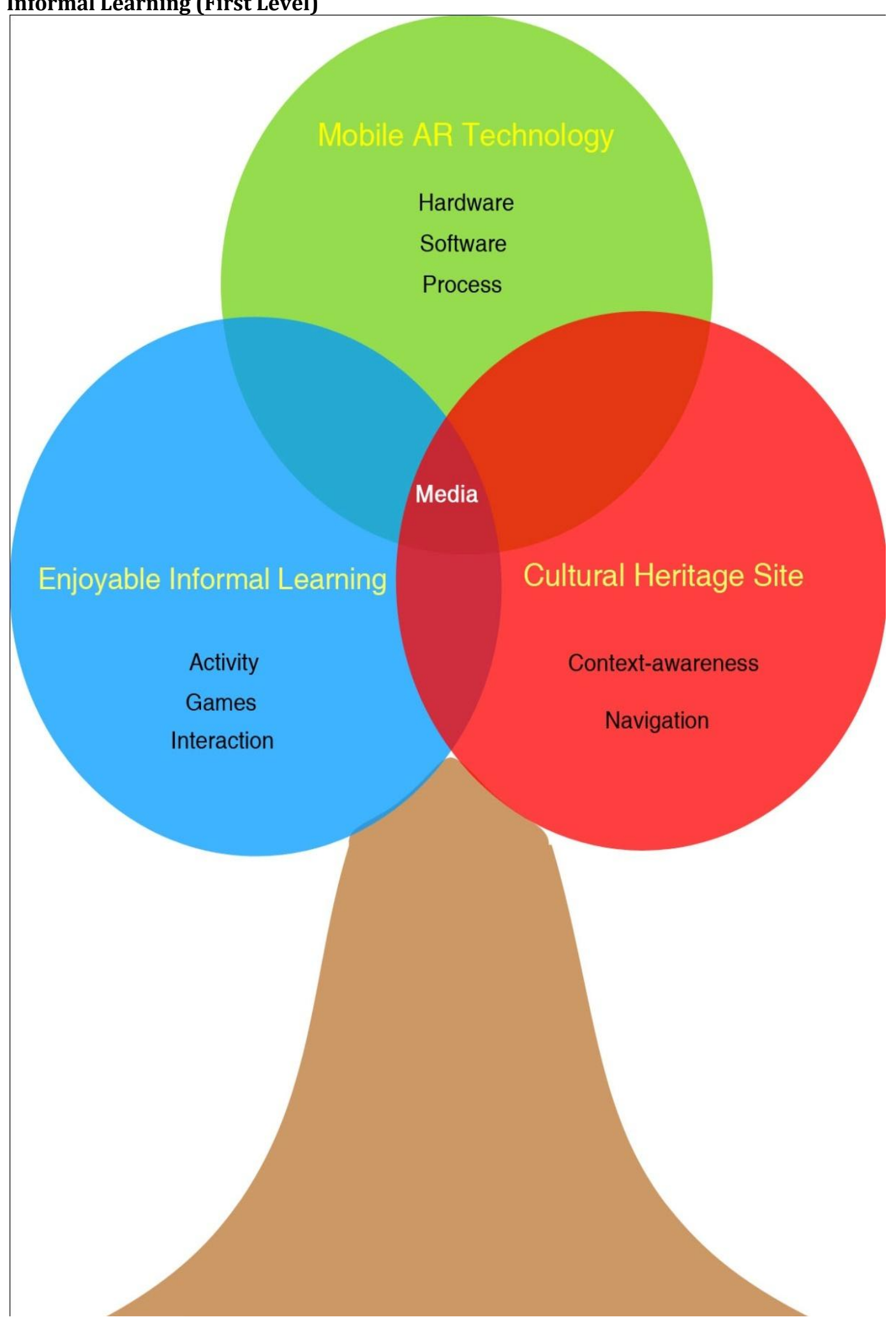


Figure 6: Proposed conceptual model of mobile AR for cultural heritage site towards enjoyable informal learning (second level)

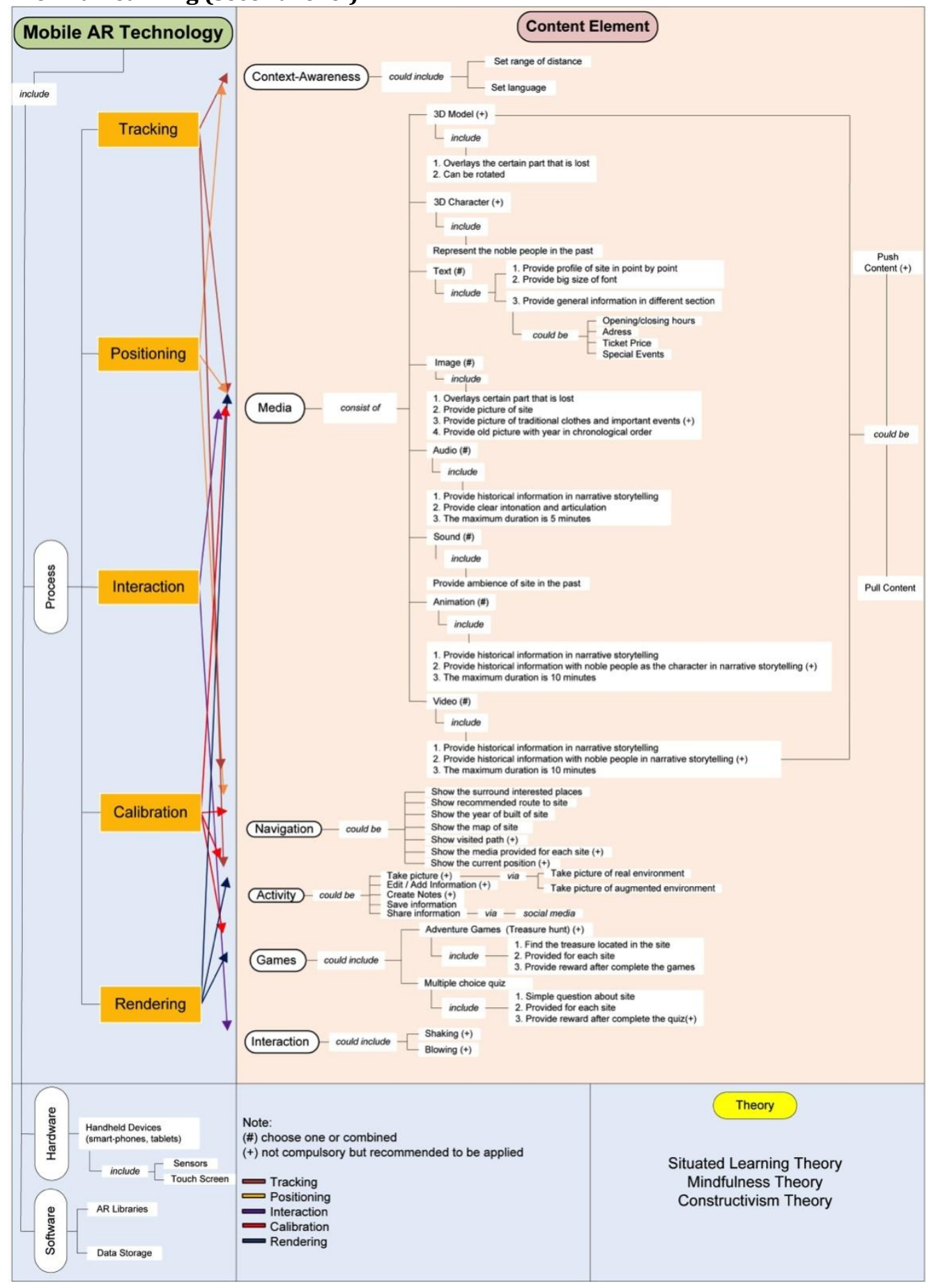

Acknowledgement: I acknowledge Lembah Bujang Archaeological Site, Kedah, for the permission for conducting the field study. I also acknowledge Ministry of Education Malaysia and Universiti Utara Malaysia (http://www.uum.edu.my/) for the research grants.

\section{References}

Azuma, R. T. (1997). A Survey of Augmented Reality. PRESENCE: Teleoperators and Virtual Environments 6(4), 355-385.

Billinghurst, M., Kato, H. \& Poupyrev, I. (2008). Tangible augmented reality. ACM SIGGRAPH ASIA 2008 Courses on - SIGGRAPH Asia '08, 1-10. doi:10.1145/1508044.1508051 
Dey, A., Abowd, G. \& Salber, D. (2001). A Conceptual Framework and a Toolkit for Supporting the Rapid Prototyping of Context-Aware Applications. Human-Computer Interaction, 16(2), 97-166. doi:10.1207/S15327051HCI16234_02

Fino, E. R., Martín-Gutiérrez, J., Fernández, M. D. M. \& Davara, E. A. (2013). Interactive Tourist Guide: Connecting Web 2.0, Augmented Reality and QR Codes. Procedia Computer Science, 25, 338-344. doi:10.1016/j.procs.2013.11.040

Höllerer, T. H. \& Feiner, S. K. (2004). Mobile Augmented Reality. In K. H \& H. A (Eds.), Telegeoinformatics: Location-Based Computing Servicesmputing Services (pp. 1-39). Taylor \& Francis Books Ltd.

Park, D., Nam, T. J. \& Shi, C. K. (2006). Designing an Immersive Tour Experience System for Cultural Tour Sites. CHI '06 Extended Abstracts on Human Factors in Computing Systems - CHI EA '06, 1193. doi:10.1145/1125451.1125675

Pendit, U. C. \& Zaibon, S. B. (2014). Enjoyable Informal Learning in Cultural Heritage Site using Mobile Augmented Reality: A Conceptual Model. Journal of Advances in Science and Technology, 2(3), 93106.

Puyuelo, M., Higón, J. L., Merino, L. \& Contero, M. (2013). Experiencing Augmented Reality as an Accessibility Resource in the UNESCO Heritage Site Called La Lonja, Valencia. Procedia Computer Science, 25, 171-178. doi:10.1016/j.procs.2013.11.021

Seo, B., Kim, K. \& Park, J. I. (2011). Augmented Reality-Based On-Site Tour Guide: A Study in Gyeongbokgung. In R. Koch \& F. Huang (Eds.), Computer Vision - ACCV 2010 Workshops (pp. 276-285). Springer Berlin Heidelberg. doi:10.1007/978-3-642-22819-3_28

Toh, Y. W., Jeung, J. H. \& Pan, Y. H. (2010). A combined user research process for designing mobile AR guide in cultural heritage. 2010 IEEE International Symposium on Mixed and Augmented Reality - Arts, Media, and Humanities, (M), 71-72. doi:10.1109/ISMAR-AMH.2010.5643287

Vallino, J. R. (1998). Interactive Augmented Reality. University of Rochester.

Wachelka, E. (2013). Techcooltour: Discover Ancient Empires with Augmented Reality. Retrieved February 27, 2014, from http://junaio.wordpress.com/2013/09/30/techcooltour-discoverancient-empires-with-augmented-reality/

Zoellner, M., Stricker, D., Bleser, G. \& Pastarmov, Y. (2007). iTACITUS - Novel Interaction and Tracking Paradigms for Mobile AR. In D. Arnold (Ed.), The European Research Network of Excellence in Open Cultural Heritage (EPOCH) (pp. 110-117). Budapest: Archaeolingua. 